\title{
Health behaviors and participation in health promotion activities among hospital staff: which occupational group performs better?
}

\author{
Shu-Ti Chiou ${ }^{1,2}$, Jen-Huai Chiang ${ }^{3,4,5}$, Nicole Huang ${ }^{6}$ and Li-Yin Chien ${ }^{7 *}$
}

\begin{abstract}
Background: Staff health behaviors affect not only their own health but also their provision of health promotion services to their patients. Although different occupational groups work in hospitals, few studies have compared health behaviors among them. The objectives of this study were to examine health behaviors, including physical activity, eating 5 portions of fruits and vegetables per day ( 5 a day), and stress adaptation, and participation in hospital-based health promotion activities by occupational groups in hospitals.

Methods: This cross-sectional survey was conducted among full-time employees in 100 hospitals across Taiwan. This analysis included 4202 physicians, 31639 nurses, 2315 pharmacists, 8161 other health professionals, and 13079 administrative personnel.

Results: Administrative personnel attended more health promotion lectures and clubs/groups than other health professionals, pharmacists and physicians, and those workers participated more than nurses. Participation in health promotion activities provided by hospitals was associated with better practice of health behaviors. After adjustment for socio-demographics and participation in health promotion activities, physicians, pharmacists, and other health professionals reported more 5 a day than administrative staff. Other health professionals reported more physical activity than administrative staff, and they reported more than physicians. Nurses reported the lowest level of physical activity, 5 a day, and stress adaptation of all occupational groups.

Conclusions: Nurses had worse health behaviors and less participation in health promotion activities than other groups. Workplace health promotion program for health professionals is needed, with special emphasis on nurses. Hospital-based health promotion programs could take the differences of occupational groups into consideration to tailor programs to the needs of different occupational groups.
\end{abstract}

Keywords: Health behaviors, Health care staff, Health promotion, Health promoting hospital, Taiwan

\section{Background}

The World Health Organization initiated the Health Promoting Hospitals (HPH) Project aiming at reorienting hospitals to integrate health promotion and education, disease prevention and rehabilitation services in curative care [1]. According to the 5 standards for assessment of implementing health promotion in hospitals, emphasis is placed on health promotion among patients, relatives, and staff [1]. In 2012, the Taiwan HPH Network

\footnotetext{
* Correspondence: lychien@ym.edu.tw

${ }^{7}$ Institute of Clinical and Community Health Nursing, National Yang-Ming University, 155 Li-Nong Street, Section 2, Bei-Tou, Taipei 11221, Taiwan Full list of author information is available at the end of the article
}

included 76 member hospitals and was one of the largest $\mathrm{HPH}$ networks internationally [2]. The Taiwan HPH approach directed Taiwanese hospital leaders' attention to staff health. Although hospitals increasingly provide health promoting activities for their staff, participation by health care staff and the effects on staff health behaviors have not been studied.

Staff health behaviors affect not only their own health but also their provision of health promotion services to their patients. Zhu et al. [3] reported that normal weight doctors and nurses were more likely than those who were overweight to provide overweight or obese patients with advice and strategies to achieve weight loss. Lobelo 
et al. [4] asserted that there is compelling evidence that the health of doctors matters and that doctors' own physical activity habits influence their clinical attitudes and counseling of patients regarding physical activity. General practitioners who smoked themselves were less likely to engage in smoking cessation for their patients [5]. Studies have reported that stress and health risks are high in healthcare workers [6,7]. Health promotion programs aimed at healthcare workers are suggested to reduce job stress, prevent burnout, improve health, and probably prevent turnover $[8,9]$.

During the past decades, different occupational groups of health professionals have been increasingly advocating a more health-promoting health services in clinical practices [10-12]. Studies have reported support for reorientation of health services in the incorporation of a greater health promotion $[13,14]$. Nonetheless, hospital or acute setting-based health professionals were less likely to engage in health promotion practices than primary health care personnel [13]. If hospital-based health professionals could practice health behaviors themselves, they could not only serve as role models but also influence their attitudes, knowledge, and skills toward health promotion, and hence provision of health promotion services to their patients [15].

Although different occupational groups work in hospitals, few studies have compared health behaviors among them. Such information could be informative in designing hospital-based health promotion programs. The objectives of this study were to examine health behaviors, including physical activity, eating 5 portions of fruits and vegetables per day ( 5 a day), and stress adaptation, and participation in hospital-based health promotion activities by occupational groups in hospitals. The association between participation in health promoting activities and health behaviors was also examined.

\section{Methods}

\section{Design and participants}

This study was a cross-sectional survey, and included all full-time staff members working in 100 hospitals across Taiwan. We invited all members of the Taiwan HPH project ( $n=66$ in 2010 ) to participate in the study. According to the distribution of accredited hospital levels of $\mathrm{HPH}$, we drew a random sample of non- $\mathrm{HPH}$ using a 1:1 ratio. Since there were $45 \mathrm{HPH}$ regional hospitals and only 40 non-HPH regional hospitals, all non- $\mathrm{HPH}$ regional hospitals were invited, which resulted in a total of 61 non-HPH hospitals. Of the 127 hospitals selected, $100(78.7 \%)$ agreed to participate in this study. Details of the study design are presented elsewhere [16].

We enquired about the number of full-time employees at the study hospitals and distributed questionnaires to each hospital. The staff members were asked to complete and return the anonymous questionnaires in the sealed envelopes provided to a collection site at the hospitals. The study protocol was approved by an Institutional review board at the Bureau of Health Promotion, Department of Health before the inception of the survey (Bureau of Health Promotion investigation number 0990800708).

The survey was conducted from May to July, 2011. A total of 98,817 questionnaires were distributed and 73,391 (74.3\%) questionnaires were returned. This analysis included 4202 physicians, 31639 nurses, 2315 pharmacists, 8161 other health professionals, and 13079 administrative personnel.

\section{Measurements}

The data were collected using a structured questionnaire that was developed specifically for this study. The questionnaire was reviewed and modified by six experts and 10 health care workers to ensure its validity.

The study variables included sociodemographic variables (age, sex, educational level, and marital status), work characteristics (accredited hospital level and $\mathrm{HPH}$ status), participation in hospital-based health promotion activities, and health behaviors (physical activity, 5 a day, and stress adaptation).

Participation in hospital-based health promotion activities related to physical activity, healthy diet, and stress adaptation was determined by asking "During the past year, did you participate in the indicated activities (including lectures, clubs/groups, and use of equipment)?" Participation in lectures was measured using a 3-point Likert scale ranging from 1 (none), 2 (a couple of times), to 3 (often). Participation in clubs/groups was measured using a 5-point Likert-scale item from 1 (none) to 5 (more than 3 times a week), with a higher score indicating more frequent attendance.

Physical activity and dietary behavior were assessed by enquiring "number of days walking more than $30 \mathrm{mi}$ nutes or equivalent physical activities during the past week" and "number of days eating 5 portions of fruits and vegetables during the past week", respectively. Those two questions were assessed using a 5-point Likert scale from 1 (0 day), 2 (1-2 days), 3 (3-4 days), 4 (5-6 days), and 5 (7 days). Stress adaptation was assessed using a selfrated level on a 5-point Likert scale from 1 (very bad), 2 (bad), 3 (still permissible), 4 (good), and 5 (very good).

\section{Data analysis}

Statistical analyses were performed using IBM SPSS Statistics version 18.0 (IBM Corp., Armonk, New York, USA). Categorical variables were characterized by percentage and frequency, while continuous variables were characterized by mean and standard deviation. Differences among occupational groups were examined by $x^{2}$ 
statistics and Kruskal Wallis tests. Generalized linear modelling was used to examine the differences in health behaviors by occupational group, with adjustment for sociodemographic characteristics and participation in health-promoting activities. Generalized linear model with one dependent variable can be considered as a multiple regression model, and it allows for the dependent variable to have a normal or non-normal distribution [17].

\section{Results}

Characteristics of the study participants are presented in Table 1. Nurses, pharmacists, and other health professionals appeared to be younger than physicians and administrative personnel $(72.4 \%$ of nurses, $63.2 \%$ of pharmacists, $58.5 \%$ of other health professionals, $51.7 \%$ of administrators, and $40.9 \%$ of physicians were $\leq$ 35 years old). Roughly $23 \%$ of doctors and over $65 \%$ of other hospital staff were women (ranging from $68.6 \%$ of pharmacists to $98.3 \%$ of nurses). Physicians were more likely to be married than those in other groups.

Physical activity, 5 a day, and stress adaptation significantly differed by occupational group in both Krusal Wallis test and Chi-squared test (Table 2). The practice level was low for all health behaviors with a mean score ranging from 2.10 to 2.99 (between 1-2 days to 3-4 days for physical activity exceeding 30 minutes and 5 a day, and ranging from bad to still permissible for stress adaptation). Physicians reported more days of 30-minute physical activity than administrative staff and other health professionals, followed by pharmacists, who all reported more days of physical activity than nurses. The rate of reporting more than 3 days exceeding 30-minute physical activity was $38.8 \%$ for physicians, $35.6 \%$ for administrative personnel, $35.4 \%$ for other health professionals, $31.8 \%$ for pharmacists, and $26.5 \%$ for nurses. Physicians reported more days of 5 a day than other health professionals, followed by pharmacists and administrators, who all reported more days than nurses.

Table 1 Characteristics of study participants; $\mathbf{n}(\%)$

\begin{tabular}{|c|c|c|c|c|c|c|}
\hline & $\begin{array}{l}\text { Physicians } \\
(\mathrm{n}=4202)\end{array}$ & $\begin{array}{c}\text { Nurses } \\
(\mathrm{n}=31639)\end{array}$ & $\begin{array}{c}\text { Pharmacists } \\
(n=2315)\end{array}$ & $\begin{array}{l}\text { Other health professionals } \\
\qquad(\mathrm{n}=\mathbf{8 1 6 1})\end{array}$ & $\begin{array}{l}\text { Administrative personnel } \\
\qquad(n=13079)\end{array}$ & $p$ \\
\hline Age & & & & & & $<.0001$ \\
\hline$<26$ & $34(0.8 \%)$ & $5172(16.7 \%)$ & $274(12.2 \%)$ & $647(8.1 \%)$ & $1028(8.1 \%)$ & \\
\hline $26-35$ & 1645 (40.1\%) & 17271 (55.1\%) & 1144 (51.0\%) & $4018(50.4 \%)$ & $5522(43.6 \%)$ & \\
\hline $36-45$ & $1215(29.6 \%)$ & $6327(20.4 \%)$ & $520(23.2 \%)$ & $2347(29.4 \%)$ & $3662(28.9 \%)$ & \\
\hline $46-55$ & $866(21.1 \%)$ & $1871(6.0 \%)$ & $253(11.3 \%)$ & 834 (10.5\%) & $1986(15.7 \%)$ & \\
\hline$>55$ & $339(8.3 \%)$ & $341(1.1 \%)$ & $52(2.3 \%)$ & $132(1.7 \%)$ & $480(3.8 \%)$ & \\
\hline Sex & & & & & & $<.0001$ \\
\hline Male & $3220(77.2 \%)$ & $529(1.7 \%)$ & $720(31.4 \%)$ & $2056(25.4 \%)$ & $2707(20.8 \%)$ & \\
\hline Female & $953(22.8 \%)$ & 30984 (98.3\%) & $1573(68.6 \%)$ & $6040(74.6 \%)$ & 10297 (79.2\%) & \\
\hline Educational level & & & & & & $<.0001$ \\
\hline High school or less & $0(0 \%)$ & $884(2.8 \%)$ & $9(0.4 \%)$ & $283(3.5 \%)$ & $2341(18.0 \%)$ & \\
\hline Vocational school & $17(0.4 \%)$ & 12845 (40.8\%) & $137(6.0 \%)$ & $1264(15.6 \%)$ & $3116(24.0 \%)$ & \\
\hline University & $3183(76.2 \%)$ & 17032 (54.0\%) & $1711(74.6 \%)$ & $5387(66.5 \%)$ & $6229(48.0 \%)$ & \\
\hline Post-graduate & 979 (23.4\%) & $754(2.4 \%)$ & 437 (19.0\%) & $1170(14.4 \%)$ & $1291(9.9 \%)$ & \\
\hline Marital status & & & & & & $<.0001$ \\
\hline Never married & 1181 (28.3\%) & 16989 (53.9\%) & 1355 (59.1\%) & $3750(46.3 \%)$ & $5544(42.7 \%)$ & \\
\hline Married & 2914 (69.7\%) & 13751 (43.7\%) & 897 (39.1\%) & $4120(50.9 \%)$ & $6965(53.7 \%)$ & \\
\hline Divorced/Widowed & $84(2.0 \%)$ & $759(2.0 \%)$ & $42(1.8 \%)$ & $230(2.8 \%)$ & 467 (3.6\%) & \\
\hline Accredited hospital level & & & & & & $<.0001$ \\
\hline Medical center & $1289(30.7 \%)$ & 8167 (25.8\%) & $581(25.1 \%)$ & $1956(24.0 \%)$ & $3269(25.0 \%)$ & \\
\hline Regional hospital & $2667(63.5 \%)$ & $20879(66.0 \%)$ & $1523(65.8 \%)$ & $5462(66.9 \%)$ & $8641(66.1 \%)$ & \\
\hline District hospital & $246(5.9 \%)$ & $2593(8.2 \%)$ & $211(9.1 \%)$ & $743(9.1 \%)$ & $1169(8.9 \%)$ & \\
\hline Certified health promoting hospital & & & & & & .11 \\
\hline No & $1850(44.0 \%)$ & $13660(43.2 \%)$ & $1026(44.3 \%)$ & $3572(43.8 \%)$ & $5823(44.5 \%)$ & \\
\hline Yes & 2352 (56.0\%) & 17979 (56.8\%) & 1289 (55.7\%) & 4589 (56.2\%) & 7256 (55.5\%) & \\
\hline
\end{tabular}

Note: Number in the cell may not match to the total $\mathrm{n}$ because of missing data. Missing data were excluded from the analysis listwise for each variable involved. 
Table 2 Health behaviors among hospital staff; $\mathbf{n}(\%)$

\begin{tabular}{|c|c|c|c|c|c|c|}
\hline & $\begin{array}{l}\text { Physicians } \\
(\mathrm{n}=4202)\end{array}$ & $\begin{array}{c}\text { Nurses } \\
(n=31639)\end{array}$ & $\begin{array}{l}\text { Pharmacists } \\
(n=2315)\end{array}$ & $\begin{array}{l}\text { Other health professionals } \\
\qquad(\mathrm{n}=\mathrm{8161})\end{array}$ & $\begin{array}{l}\text { Administrative personnel } \\
\qquad(n=13079)\end{array}$ & p \\
\hline \multicolumn{7}{|c|}{ Number of days exceeding 30 minutes walking or equivalent physical activity during past week } \\
\hline Scale; M (SD) & $2.40(1.06)$ & $2.10(1.10)$ & $2.27(1.09)$ & $2.35(1.12)$ & $2.34(1.11)$ & $<.0001$ \\
\hline 0 day & $785(18.7 \%)$ & $10646(33.6 \%)$ & $558(24.1 \%)$ & $1907(23.4 \%)$ & $2969(22.7 \%)$ & $<.0001$ \\
\hline $1-2$ days & $1787(42.5 \%)$ & $12607(39.8 \%)$ & $1021(44.1 \%)$ & $3357(41.1 \%)$ & $5459(41.7 \%)$ & \\
\hline 3-4 days & $1008(24.0 \%)$ & $4464(14.1 \%)$ & $422(18.2 \%)$ & $1536(18.8 \%)$ & $2574(19.7 \%)$ & \\
\hline 5-6 days & $398(9.5 \%)$ & $2401(7.6 \%)$ & $178(7.7 \%)$ & $893(10.9 \%)$ & $1347(10.3 \%)$ & \\
\hline 7 days & $224(5.3 \%)$ & $1521(4.8 \%)$ & $136(5.9 \%)$ & $468(5.7 \%)$ & $730(5.6 \%)$ & \\
\hline \multicolumn{7}{|c|}{ Number of days having 5 portions of fruits and vegetables during past week } \\
\hline Scale; M (SD) & $2.99(1.10)$ & $2.60(1.06)$ & $2.82(1.07)$ & $2.88(1.09)$ & $2.82(1.09)$ & $<.0001$ \\
\hline 0 day & $341(8.1 \%)$ & $4286(13.5 \%)$ & $219(9.5 \%)$ & $749(9.2 \%)$ & $1335(10.2 \%)$ & $<.0001$ \\
\hline 1-2 days & $1112(26.5 \%)$ & $11873(37.5 \%)$ & $733(31.7 \%)$ & $2397(29.4 \%)$ & $4017(30.7 \%)$ & \\
\hline 3-4 days & $1436(34.2 \%)$ & 9662 (30.5\%) & $790(34.1 \%)$ & $2798(34.3 \%)$ & $4437(33.9 \%)$ & \\
\hline 5-6 days & $887(21.1 \%)$ & $3916(12.4 \%)$ & 387 (16.7\%) & $1511(18.5 \%)$ & $2237(17.1 \%)$ & \\
\hline 7 days & $426(10.1 \%)$ & $1902(6.0 \%)$ & $186(8.0 \%)$ & $706(8.7 \%)$ & $1053(8.1 \%)$ & \\
\hline \multicolumn{7}{|c|}{ Perceived adequacy of stress adaptation } \\
\hline Scale; M (SD) & $2.71(0.79)$ & $2.53(0.76)$ & $2.66(0.73)$ & $2.68(0.73)$ & $2.69(0.73)$ & $<.0001$ \\
\hline Very bad & $353(8.5 \%)$ & $3691(11.8 \%)$ & $188(8.2 \%)$ & $601(7.4 \%)$ & $969(7.5 \%)$ & $<.0001$ \\
\hline $\mathrm{Bad}$ & $938(22.5 \%)$ & 8807 (28.1\%) & $545(23.8 \%)$ & $1945(24.0 \%)$ & $3063(23.6 \%)$ & \\
\hline Still permissible & $2504(60.2 \%)$ & $17579(56.2 \%)$ & $1441(62.8 \%)$ & $5020(62.1 \%)$ & $8067(62.2 \%)$ & \\
\hline Good & $296(7.1 \%)$ & 1088 (3.5\%) & $102(4.4 \%)$ & 455 (5.6\%) & 758 (5.8\%) & \\
\hline Very good & 69 (1.7\%) & $140(0.4 \%)$ & 18 (0.8\%) & 67 (0.8\%) & $121(0.9 \%)$ & \\
\hline
\end{tabular}

Note: $\mathrm{p}$ value was from Kuskal Wallis test or $X^{2}$ test as appropriate.

The rate of reporting more than 5 days of practicing 5 a day was $31.2 \%$ for physicians, $27.2 \%$ for other health professionals, $25.2 \%$ for administrative personnel, $24.7 \%$ for pharmacists, and $18.4 \%$ for nurses. Nurses had lower stress adaptation than all other groups. The rate of reporting stress adaptation as bad or very bad was $39.9 \%$ for nurses and 31\% to 32\% for other professional groups.

Participation in health promotion activities by occupational group is presented in Table 3 . The participation level was low for all activities with a mean score ranging from 1.11 to 1.56 (ranging from none to a couple of times). Administrative personnel attended health promotion lectures and participated in clubs more often than other health professionals, and these staff participated more than pharmacists and physicians. Nurses participated the least, except for attending lectures on stress adaptation. Nurses attended lectures on stress adaptation more often than other occupational groups. Physicians

Table 3 Hospital staff participation in health promotion activities provided by hospitals; mean (SD)

\begin{tabular}{|c|c|c|c|c|c|c|}
\hline & $\begin{array}{l}\text { Physicians } \\
(\mathrm{n}=4202)\end{array}$ & $\begin{array}{c}\text { Nurses } \\
(\mathrm{n}=31369)\end{array}$ & $\begin{array}{c}\text { Pharmacists } \\
(n=2315)\end{array}$ & $\begin{array}{l}\text { Other health professionals } \\
\qquad(\mathrm{n}=\mathbf{8 1 6 1})\end{array}$ & $\begin{array}{l}\text { Administrative personnel } \\
\qquad(n=13079)\end{array}$ & p \\
\hline Attend lectures & $1.25(0.48)$ & $1.25(0.46)$ & $1.24(0.47)$ & $1.29(0.49)$ & $1.41(0.55)$ & $<0.0001$ \\
\hline Participation in sports-related clubs & $1.23(0.62)$ & $1.12(0.46)$ & $1.27(0.72)$ & $1.25(0.68)$ & $1.29(0.74)$ & $<0.0001$ \\
\hline Use of gym or sports equipment & $1.56(0.99)$ & $1.34(0.73)$ & $1.36(0.77)$ & $1.49(0.90)$ & $1.39(0.83)$ & $<0.0001$ \\
\hline Attend lectures & $1.18(0.44)$ & $1.17(0.40)$ & $1.14(0.38)$ & $1.20(0.46)$ & $1.24(0.46)$ & $<0.0001$ \\
\hline $\begin{array}{l}\text { Participation in weight-control groups } \\
\text { or activities }\end{array}$ & $1.14(0.39)$ & $1.13(0.35)$ & $1.13(0.36)$ & $1.17(0.41)$ & $1.21(0.44)$ & $<0.0001$ \\
\hline Attend lectures & $1.24(0.46)$ & $1.48(0.52)$ & $1.24(0.45)$ & $1.30(0.48)$ & $1.38(0.52)$ & $<0.0001$ \\
\hline $\begin{array}{l}\text { Participation in recreational or } \\
\text { service clubs }\end{array}$ & $1.17(0.52)$ & $1.11(0.40)$ & $1.16(0.55)$ & $1.17(0.53)$ & $1.23(0.64)$ & $<0.0001$ \\
\hline
\end{tabular}

Note: $p$ value from Krusal Wallis test. 
used gyms and sports equipment more often than other occupational groups.

Generalized linear models for the 3 health behaviors are presented in Table 4. Participation in health promotion activities was positively related to the practice of health behaviors. Married staff reported better 5 a day and stress adaptation, but less days of physical activity exceeding 30-minutes than others. Staff with higher educational levels reported better 5 a day and stress adaptation, while they reported fewer days of physical activity exceeding 30-minutes. There were no significant differences in 5 a day and stress adaption between staff of $\mathrm{HPH}$ and non-HPH hospitals. Staff of HPH hospitals reported more days exceeding 30-minutes physical activity than non-HPH hospitals. After adjustment for those variables, nurses reported the lowest level of physical activity, healthy diet, and stress adaptation of all occupational groups. Physicians reported less physical activity but more days of 5 a day than administrative staff. Pharmacists reported more days of 5 a day than administrative staff. Other health professionals reported more physical activity and days of 5 a day than administrative staff.

\section{Discussion}

We found that nurses had the worst health behaviors and lowest participation in health promotion activities of all occupational groups working in hospitals. A previous study reported that physicians and nurses felt the same

Table 4 Generalized linear models for health behaviors

\begin{tabular}{|c|c|c|c|c|c|c|c|c|c|}
\hline & \multicolumn{3}{|c|}{$\begin{array}{l}\text { Number of days exceeding } \\
30 \text { minutes physical } \\
\text { activity during past week }\end{array}$} & \multicolumn{3}{|c|}{$\begin{array}{l}\text { Number of days having } 5 \\
\text { portions of fruits and } \\
\text { vegetables during past week }\end{array}$} & \multicolumn{3}{|c|}{$\begin{array}{l}\text { Perceived adequacy of } \\
\text { stress adaptation }\end{array}$} \\
\hline & Estimate (S.E.) & 95\% C.I. & $\overline{P \text {-value }}$ & Estimate (S.E.) & 95\% C.I. & $\overline{P \text {-value }}$ & Estimate (S.E.) & 95\% C.I. & P-value \\
\hline \multicolumn{10}{|l|}{ Professional background } \\
\hline Physicians & $-0.07(0.02)$ & $-0.11,-0.03$ & .002 & $0.11(0.02)$ & $0.07,0.15$ & $<.0001$ & $-0.01(0.02)$ & $-0.04,0.02$ & .34 \\
\hline Nurses & $-0.10(0.01)$ & $-0.12,-0.07$ & $<.0001$ & $-0.12(0.01)$ & $-0.15,-0.10$ & $<.0001$ & $-0.13(0.01)$ & $-0.15,-0.12$ & $<.0001$ \\
\hline Pharmacists & $-0.04(0.03)$ & $-0.09,0.01$ & .12 & $0.07(0.02)$ & $0.02,0.12$ & .006 & $-0.01(0.02)$ & $-0.04,0.03$ & .60 \\
\hline Other health professionals & $0.06(0.02)$ & $0.03,0.09$ & $<.0001$ & $0.09(0.02)$ & $0.06,0.12$ & $<.0001$ & $-0.02(0.01)$ & $-0.01,0.04$ & .16 \\
\hline \multicolumn{10}{|l|}{ Age } \\
\hline $26-35$ & $-0.14(0.01)$ & $-0.17,-0.11$ & $<.0001$ & $0.11(0.01)$ & $0.09,0.14$ & $<.0001$ & $0.01(0.01)$ & $-0.02,0.03$ & .60 \\
\hline $36-45$ & $-0.09(0.02)$ & $-0.13,-0.06$ & $<.0001$ & $0.33(0.02)$ & $0.30,0.37$ & $<.0001$ & $0.04(0.01)$ & $0.02,0.07$ & .001 \\
\hline $46-55$ & $0.14(0.02)$ & $0.10,0.19$ & $<.0001$ & $0.48(0.02)$ & $0.43,0.52$ & $<.0001$ & $0.15(0.02)$ & $0.12,0.18$ & $<.0001$ \\
\hline$>55$ & $0.34(0.03)$ & $0.27,0.41$ & $<.0001$ & $0.60(0.03)$ & $0.54,0.67$ & $<.0001$ & $0.23(0.02)$ & $0.18,0.28$ & $<.0001$ \\
\hline \multicolumn{10}{|l|}{ Sex } \\
\hline Female & $-0.35(0.02)$ & $-0.38,-0.32$ & $<.0001$ & $0.08(0.01)$ & $0.05,0.11$ & $<.0001$ & $-0.03(0.01)$ & $-0.05,-0.01$ & .01 \\
\hline \multicolumn{10}{|l|}{ Educational level } \\
\hline Vocational school & $-0.16(0.02)$ & $-0.21,-0.12$ & $<.0001$ & $.00(0.02)$ & $-0.04,0.04$ & .97 & $-0.03(0.02)$ & $-0.06,-0.002$ & .04 \\
\hline University & $-0.22(0.02)$ & $-0.26,-0.18$ & $<.0001$ & $0.03(0.02)$ & $-0.007,0.08$ & .11 & $0.002(0.01)$ & $-0.03,0.03$ & .87 \\
\hline Graduate school & $-0.24(0.03)$ & $-0.29,-0.18$ & $<.0001$ & $0.14(0.03)$ & $0.10,0.19$ & $<.0001$ & $0.07(0.02)$ & $0.03,0.10$ & $<.0001$ \\
\hline \multicolumn{10}{|l|}{ Marital status } \\
\hline Married & $-0.09(0.01)$ & $-0.11,-0.07$ & $<.0001$ & $0.18(0.01)$ & $0.16,0.21$ & $<.0001$ & $0.02(0.008)$ & $0.003,0.03$ & .02 \\
\hline Divorce/Widowed & $0.01(0.03)$ & $-0.04,0.07$ & .63 & $0.02(0.03)$ & $-0.04,0.08$ & .47 & $-0.01(0.02)$ & $-0.05,0.03$ & .58 \\
\hline \multicolumn{10}{|l|}{ Accredited hospital level } \\
\hline Regional hospital & $0.00(0.01)$ & $-0.02,0.02$ & .98 & $0.03(0.02)$ & $-0.001,0.07$ & .06 & $0.00(0.01)$ & $-0.01,0.02$ & .70 \\
\hline District hospital & $0.02(0.02)$ & $-0.02,0.05$ & .86 & $0.03(0.01)$ & $0.01,0.05$ & .002 & $-0.01(0.01)$ & $-0.03,0.02$ & .47 \\
\hline \multicolumn{10}{|l|}{$\begin{array}{l}\text { Certified health promoting } \\
\text { hospital }\end{array}$} \\
\hline Yes & $0.02(0.01)$ & $0.00,0.04$ & .04 & $0.01(0.01)$ & $-0.01,0.03$ & .24 & $-0.006(0.01)$ & $-0.02,0.01$ & .31 \\
\hline \multicolumn{10}{|c|}{ Participation in health promotion activities provided by hospitals } \\
\hline Attend lectures & $0.12(0.01)$ & $0.10,0.14$ & $<.0001$ & $0.12(0.01)$ & $0.10,0.14$ & $<.0001$ & $0.14(0.01)$ & $0.12,0.15$ & $<.0001$ \\
\hline $\begin{array}{l}\text { Participation in clubs/ } \\
\text { groups }\end{array}$ & $0.08(0.01)$ & $0.06,0.10$ & $<.0001$ & $0.07(0.01)$ & $0.05,0.09$ & $<.0001$ & $0.06(0.01)$ & $0.05,0.07$ & $<.0001$ \\
\hline
\end{tabular}


level of job stress, and they experienced higher levels of stress than administrative workers in hospitals [6]. Although they had the same stress level, nurses had less support from supervisors and coworkers than physicians. As a result, nurses showed higher stress responses than physicians and administrative workers in hospitals [6]. Our results concurred with a previous study showing that nurses reported worse stress adaptation than other occupational groups [6]. In addition, we found that nurses also reported the lowest level of physical activity and 5 a day. Previous researchers asserted that workrelated stress was negatively associated with health behaviors [18,19]. Thus poor stress adaption and high stress levels may be contributory factors for the low physical activity and 5 a day among nurses. Since the nursing shortage is a serious issue in Taiwan as well as in many other countries $[20,21]$, hospital administrators should be aware of the local understanding of occupational stressors and productively engage nurses in identifying initiatives to reduce occupational stress, improve stress management, and promote health, which could help prevent burnout and decrease turnover [9,22,23]. The finding that nurses attended lectures on stress adaptation more often than other occupational groups suggests that hospital administrators and nurses were aware of the problem of job stress among nurses. Nonetheless, effective strategies other than lectures should be developed.

Mobilizing health promotion among nurses could have great impact on population health since nurses are the largest health professional workforce [24]. Previous studies reported a lack of understanding of the nature and practice of health promotion among nurses in hospital settings [25,26]. Many nurses defined and practiced health promotion in the narrower terms of health education, i.e., isolated information-giving and disease prevention activities alone $[27,28]$. We felt that nurses could be empowered to reflect on their own practice of health behaviors as an individual and a professional group and incorporate systems thinking and socio-ecological models of health promotion into their clinical nursing practices [24]. Further studies are needed to develop and evaluate innovative programs in this aspect.

Administrative workers attended health promotion lectures and participated in clubs/groups more often than other groups and their level of physical activity appeared to be better, but their consumption of 5 a day appeared to be worse than for physicians and pharmacists. Physicians used gyms and sports equipment more often than other occupational groups, but they participated in lectures and clubs/groups less often. Those results reflected differences among occupational groups in hospitals. Hospital-based health promotion programs could take differences in occupational groups into consideration to tailor programs to the needs of different occupational groups.

In general, hospital workers practiced physical activity, 5 a day, and stress adaption at a level that is less than desirable. Participation in health promotion activities was related to better health behaviors among hospital staff, but their level of participation was generally low. More effort is needed to motivate staff to participate in hospital-based health promotion activities, especially nurses, pharmacists, and physicians. Workplace health promotion programs for health professionals are needed, with special emphasis on nurses.

It was noted that $0.4 \%$ of physicians reported an educational level of vocational schools; $0.4 \%$ of pharmacists, $2.89 \%$ of nurses, and $3.5 \%$ of other health professionals reported an educational level of high school; $18.0 \%$ of administrative personnel reported an educational level of high school or less. Majority of the physicians in Taiwan graduated with a medical doctor degree (University). However, very few physicians could graduate long-time ago. Back in that time, people with a vocational school degree from medical vocational school plus years of medical practices could take qualification examinations and became doctors. Some high schools in Taiwan offered vocational training. Health professionals besides doctors could hold a high school degree if they received vocational training as a health professional in high schools. Administrative personnel could receive an educational level of high school or less. The report of educational level among our participants was within possible ranges, though the distribution would be different from other country context.

This study was limited by the use of a cross-sectional design and causal relationships could not be established. The data were self-reported and we had no way to validate the answers. The study variables were measured by questions developed specifically for this study, rather than standard instruments, which could increase the likelihood of misclassification and limits comparisons with other studies. The study results could be bound to the Taiwanese hospital context and may not be applicable to other systems across the world.

\section{Conclusions}

Of the occupational groups working in hospitals, nurses had the lowest levels of physical activity, 5 a day, and stress adaptation. Nurses attended lectures about stress more often than the other occupational groups, but their stress adaption was poorer. Administrative personnel attended more lectures and clubs/groups related to physical activity and healthy diet than other occupational groups. Hospitals workers practiced health behaviors and participated in health promoting activities at a low level. Participation in health promotion activities provided by 
hospitals was positively associated with the practice of health behaviors. Workplace health promotion program for health professionals is needed, with special emphasis on nurses. Hospital-based health promotion programs could take the differences of occupational groups into consideration to tailor programs to their needs.

\section{Competing interests}

The authors declare that they have no competing interests.

\section{Authors' contributions}

STC conceived of the study, participated in the design of the study, and drafted the manuscript. JHC performed the statistical analysis under the supervision of LYC. NH participated in the design of the study and helped interpretation of the study results. LYC participated in the design and coordination of the study and helped to draft and revise the manuscript. All authors read and approved the final manuscript.

\section{Acknowledgement}

This study was funded by the Bureau of Health Promotion (BHP), Department of Health, Taiwan (DOH100-HP-2401).

\section{Author details}

${ }^{1}$ Health Promotion Administration, Ministry of Health and Welfare, Taipei, Taiwan. ${ }^{2}$ Institute of Public Health, National Yang-Ming University, Taipei, Taiwan. ${ }^{3}$ Alternative Military Service - Surveillance and Research Division, Health Promotion Administration, Ministry of Health and Welfare, Taipei, Taiwan. ${ }^{4}$ Management Office for Health Data, China Medical University Hospital, Taichung, Taiwan. ${ }^{5}$ Research Center for Chinese Medicine \& Acupuncture, China Medical University, Taichung, Taiwan. ${ }^{6}$ Institute of Hospital and Health Care Administration, National Yang-Ming University, Taipei, Taiwan. 'Institute of Clinical and Community Health Nursing, National Yang-Ming University, 155 Li-Nong Street, Section 2, Bei-Tou, Taipei 11221, Taiwan.

Received: 22 November 2013 Accepted: 29 September 2014 Published: 22 October 2014

\section{References}

1. Regional Office for Europe, World Health Organization: Standards for health promotion in hospitals: Development of indicators for a self-assessment tool. 2004. http://www.euro.who.int/_data/assets/pdf_file/0006/99762/e82490.pdf.

2. Taiwan Society of Health Promoting Hospitals. http://www.hph.org.tw/.

3. Zhu DQ, Norman IJ, While AE: The relationship between doctors' and nurses' own weight status and their management practices: a systematic review. Obes Rev 2011, 12:459-469.

4. Lobelo F, Duperly J, Frank E: Physical activity habits of doctors and medical students influence their counseling practices. Br J Sports Med 2009, 43:89-92.

5. Stead M, Angus K, Holme I, Cohen D, the PESCE European Research Team, Tait G: Factors influencing European GPs' engagement in smoking cessation: a multi-county literature review. Br J Gen Pract 2009, 59(566):682-690.

6. Ito S, Fujita S, Seto K, Kitazawa T, Matsumoto K, Hasegawa T: Occupational stress among healthcare workers in Japan. Work 2014, 49(2):225-234.

7. Tsai YC, Liu CH: Factors and symptoms associated with work stress and health-promoting lifestyles among hospital staff: a pilot study in Taiwan. BMC Health Serv Res 2012, 12:199.

8. Van Wyk BE, Pillay-Van Wyk V: Preventive staff-support interventions for health workers. Cochrane Database Syst Rev 2010, 2010:CD003541.

9. Chan CW, Perry L: Lifestyle health promotion interventions for the nursing workforce: a systematic review. J Clin Nurs 2012, 21:2247-2261.

10. O'Donoghue G, Cunningham C, Murphy F, Woods C, Aagaard-Hansen J: Assessment and management of risk factors for the prevention of lifestyle-related needs of primary care physiotherapists in the Republic of Ireland. Physiotherapy 2014, 100(2):116-122.

11. Whitehead D: Health promoting hospitals: the role and function of nursing. J Clin Nurs 2005, 14(1):20-27.

12. Brotons C, Bjorkelund C, Bulc M, Ciurana R, Godycki-Cwirko M, Jurgova E, Kloppe P, Lionis C, Mierzecki A, Pineiro R, Pullerits L, Sammut MR, Sheehan
M, Tataradze R, Thireos EA, Vuchark J, EUROPREV network: Prevention and health promotion in clinical practice: the views of general practitioners in Europe. Prev Med 2005, 40(5):595-601.

13. Johansson H, Stenlund H, Lundstrom L, Weinehall L: Reorientation to more health promotion in health services: a study of barriers and possibilities from the perspective of health professionals. J Multidiscip Healthc 2010, 3:213-224.

14. Wise M, Nutbeam D: Enabling the systems transformation: what progress has been made in re-orienting health services. Promot Educ 2007, 14(Suppl 2):23-27.

15. Ampt AJ, Amoroso C, Harris MF, McKenzie SH, Rose VK, Taggart JR: Attitudes, norms and controls influencing lifestyle risk factor management in general practice. BMC Fam Prac 2009, 10:59.

16. Chiou ST, Chiang JH, Huang N, Wu CH, Chien LY: Health issues among nurses in Taiwanese hospitals: National survey. Int I Nurs Stud 2013, 50:1377-1384.

17. McCullagh P: Generalized linear models. Eur J Oper Res 1984, 16:285-292.

18. Nahm ES, Warren J, Zhu S, An M, Brown J: Nurses' self-care behaviors related to weight and stress. Nurs Outlook 2012, 60:e23-e31.

19. Wang LJ, Chen CK, Hsu SC, Lee SY, Wang CS, Yeh WY: Active job, healthy job? Occupational stress and depression among hospital physicians in Taiwan. Ind Health 2011, 49:173-184.

20. Hayes LJ, O'Brien-Pallas L, Duffield C, Shamian J, Buchan J, Hughes F, Laschinger KHS, North N: Nurse turnover: A literature review - an update. Int J Nurs Stud 2012, 49:887-905.

21. Kao CC: Multi-aspects of nursing manpower in Taiwan. Cheng Ching Med J 2011, 7:41-46.

22. Bhui KS, Dinos S, Stansfeld SA, White PD: A synthesis of the evidence for managing stress at work: a review of the reviews reporting on anxiety, depression, and absenteeism. J Environ Public Health 2012, 2012:515874.

23. Happel B, Dwyer T, Reid-Searl K, Burke KJ, Caperchione CM, Gaskin CJ: Nurses and stress: recognizing causes and seeking solutions. J Nurs Manag 2013, 21:638-647.

24. Whitehead D, Irvine F: Ottwa $25+$ 'All aboard the dazzling bandwagondeveloping personal skills: what remains for the future. Health Promot Int 2011, 26(Suppl 2):245-252.

25. Casey D: Findings from non-participant observational data concerning health promoting nursing practice in the acute hospital setting focusing on generalist nurse. J Clin Nurs 2007, 16:580-592.

26. Casey D: Nurses' perceptions, understanding and experiences of health promotion. J Clin Nurs 2007, 16:1039-1049.

27. Berg GV, Hedelin B, Sarvimaki A: A holistic approach to the promotion of older hospital patients' health. Int Nurs Rev 2005, 52(1):73-80.

28. Kelley $\mathrm{K}$, Abraham C: Health promotion for people aged over 65 years in hospitals: nurses' perceptions about their role. J Clin Nurs 2007, 16:569-579.

doi:10.1186/1472-6963-14-474

Cite this article as: Chiou et al.: Health behaviors and participation in health promotion activities among hospital staff: which occupational group performs better?. BMC Health Services Research 2014 14:474.

\section{Submit your next manuscript to BioMed Central and take full advantage of:}

- Convenient online submission

- Thorough peer review

- No space constraints or color figure charges

- Immediate publication on acceptance

- Inclusion in PubMed, CAS, Scopus and Google Scholar

- Research which is freely available for redistribution 